\title{
Motor Skill Development and Youth Physical Activity: A Social Psychological Perspective
}

\author{
Maureen R. Weiss \\ University of Minnesota
}

\begin{abstract}
Children and youth participate in physical activities to develop and demonstrate physical competence, attain social acceptance and approval, and experience enjoyment. Satisfying these motives enhances interest in sustaining physical activity, which contributes to improved motor skills, self-confidence, social relationships, and other positive outcomes. My essay explores motor skill development and youth physical activity through a social psychological lens and the benefits of integrating scientific knowledge from our respective fields to inform research and professional practice. Motor development and sport psychology researchers can collaborate to address critical issues related to motor and perceived competence and physical activity. I recommend five ways for integrating knowledge: (1) applying social psychological theory to guide research questions, (2) using more longitudinal designs, (3) using a variety of quantitative and qualitative methods, (4) designing studies on physical literacy, and (5) employing a positive youth development (PYD) approach for improving motor and social-emotional skills. These efforts can assist teachers, coaches, and parents in creating opportunities for youth to learn and improve fundamental motor and sport skills and to achieve feelings of competence, autonomy, relatedness, and joy for motivating a lifetime of physical activity.
\end{abstract}

Keywords: developmental, motivation, motor competence, perceived competence, socioenvironmental influences

I have always taken a developmental perspective in my scholarly work on youth motivation and physical activity, so I am pleased with the opportunity to highlight the benefits of integrating knowledge from motor development and sport psychology. Integrating theories and research can lead to a fuller understanding of the intrapersonal and socioenvironmental factors that influence motor and psychosocial development and physical activity. It also can enhance translation of research to best practices for teaching youth in motor skill programs, physical education, organized sport, and other activity contexts. I chose an integration

Weiss (mrweiss@umn.edu) is with the School of Kinesiology, University of Minnesota, Minneapolis, MN, USA. 
theme because it is central to the goals of the International Motor Development Research Consortium (I-MDRC). ${ }^{1}$ These include: (a) join researchers from various backgrounds and countries to discuss how to advance the field of motor development, (b) address philosophical questions, share ideas about developmental research agendas, and discuss research findings, and (c) develop strategies to increase scholarly impact of our research and develop meaningful collaborations (italics mine).

I first want to situate the social contexts and experiences that shaped my developmental perspective in research and practice. As a university student, I coached youth sports for the local parks and recreation program. My kids ranged in age from second graders to seniors in high school, providing considerable variability between and within age groups in physical, cognitive, and emotional maturity. I was continuously challenged to seek effective strategies for positively impacting motor skill and psychosocial development. Five years of coaching youth sports inspired me to pursue graduate work at Michigan State University, where I was fortunate to have two mentors in different areas of expertise-Dan Gould and Vern Seefeldt - and a research assistantship in the Institute for the Study of Youth Sports. I was afforded valuable opportunities for in-depth study of children's motor and psychosocial development in physical activity contexts. These experiences enhanced my appreciation for integrating knowledge from motor development and sport psychology and resulted in my dissertation on developmental modeling effects on motor performance. I also had doctoral-student peers in motor development and sport psychology—Beverly Ulrich, Thelma Horn, Crystal Branta, and Dale Ulrich. We supported and influenced each other's research, goals, and careers, as will become apparent.

As a professor at the University of Oregon, I spent 15 summers as Director of the Children's Summer Sports Program (CSSP), a 6-week motor skill and selfconfidence development program for 5- to 12-year-old boys and girls. A sampling approach offered youth many developmentally appropriate activities to foster fundamental motor and specific sport skills. Instructors were trained to ensure that skills were taught using effective feedback to build competence and confidence in young learners. CSSP was my naturalistic laboratory and we conducted many studies on psychological (e.g., perceived competence) and socioenvironmental (e.g., coach and peer influence) factors affecting physical activity motivation (Weiss, 2008). We conducted a field-based intervention study showing the positive effects of a mastery motivational climate on motor skills, perceived competence, and intrinsic motivation (Theeboom, De Knop, \& Weiss, 1995), which initiated interest among motor development researchers (Rudisill, 2016).

My experiences in these social contexts (coaching youth, graduate work in multiple subdisciplines, directing a children's skill development program) were instrumental in shaping my philosophy and explain why I view motor skill development and physical activity through a social psychological lens. With this backdrop, my overall intent in this essay is to summarize theories and research that can link the fields of motor development and sport psychology to advance the knowledge base on motor and perceived competence and physical activity. I begin with situating motor development within broader human development models that consider the interaction of individual and socioenvironmental factors to explain behavior change over time. Second, I discuss historical efforts encouraging the 
integration of motor behavior and sport psychology perspectives. Third, I review motor development frameworks, metaphors, and models that guide the body of knowledge on children's motor skill development and physical activity, followed by a fourth section on motor development research on motor and perceived competence and physical activity. The fifth section is devoted to a socialpsychological lens on youth physical activity-competence-based theories and research on intrapersonal (e.g., perceived competence) and socioenvironmental (e.g., significant adults) predictors of physical activity motivation. Finally, I provide several ideas for how motor development and sport psychology researchers can collaborate to enhance scholarly impact and professional practice related to motor and perceived competence and physical activity.

\section{Motor Development Within Interactional Models of Human Development}

Clark and Whitall (1989) define motor development as, “. . . the changes in motor behavior over the lifespan and the process(es) which underlie these changes" (p. 194). Clark (2005) further accentuated that an interactional approach is necessary to understand motor skill development-motor behavior changes through an interactive process between the individual's biological constraints (i.e., nature) and environmental and life experiences (i.e., nurture). Similarly, Malina $(2008,2014)$ maintains that motor competence-defined as acquiring and fine-tuning skillfulness in a variety of movement activities-involves the interaction between neuromuscular maturation and experiences within individuals' social and physical environments (e.g., home, school, community). The interplay of intrapersonal characteristics and socioenvironmental factors to explain motor behavior over time offers a strong rationale for integrating knowledge across subdisciplines to increase understanding of the relationships among motor and perceived competence and physical activity.

Two comprehensive models of human development offer relevant frameworks for understanding change in motor behavior over time. Bronfenbrenner's (1977) ecological systems model conceptualizes developmental change in attitudes, beliefs, and behaviors as a result of continuous interactions within social, environmental, and cultural contexts. The model portrays a series of concentric layers that depict the social systems that interact with the individual's biological and psychological attributes. The most proximal layer (microsystem) includes the child's immediate social and physical environment, such as family, school, and neighborhood. The next layer (mesosystem) entails interrelationships among two or more social systems, such as between family and school experiences. The exosystem comprises indirect influences on the child's development, such as community, economic, and political sources (e.g., policies regarding requirements for physical education). The most distal layer (macrosystem) entails the cultural attitudes, norms, and ideologies within the society in which the child resides (e.g., achievement domains prioritized by certain cultures). Time, or the chronosystem, permeates all layers and signifies developmental change as a result of environmental events and historical transitions. For example, female sport 
participation in the U.S. is dramatically higher since passage of Title IX nearly 50 years ago.

Sameroff (2010) proposed a unified theory of development highlighting the dynamic processes by which behavioral change occurs. His biopsychosocial ecological systems model accentuates the interaction of individuals' psychological (e.g., social competence) and biological (e.g., neurophysiology) processes with the social ecologies affecting development, including family, school, community, and broader society. Behavior change from infancy to adulthood is expressed as a growth model, or quantitative increases in biopsychological aspects, and as a development model, or qualitative change in the relationships among biopsychosocial aspects. Children with similar characteristics can have different outcomes depending on promotive and risk factors existing within the child's social ecology (e.g., family, community). He also recommended integrating perspectives from disciplines such as sociology and anthropology to understand how development varies based on disparate opportunities or cultural meanings attached to behaviors.

These two human development models portray behavioral change over time as the dynamic interaction among intrapersonal, interpersonal, and broader sociocultural contexts. They emphasize the integration of individual difference and socioenvironmental factors to explain behavior and are applicable for understanding the processes that explain continuity or change in children's motor competence and physical activity over time. Sameroff's (2010) recommendation to integrate knowledge from sociology and anthropology resonates with Malina's (2008) biocultural perspective, in which biological maturity, practice opportunities, gender expectations, and socioenvironmental and cultural experiences collectively explain motor skill development and physical activity levels.

Merging perspectives from multiple disciplines to understand motor behavior change over time was echoed by Clark (2017): "Importantly, we should remember that development is a scientific 'perspective' on human behavior. One can be a developmental sport psychologist (Weiss, 2004) or developmental exercise physiologist (Rowland, 1996). It is not about the age of the participants you study (i.e., infants, children), it is about the questions you ask" (p. 237). Motor development and sport psychology scholars are interested in similar questions such as: (a) What processes are related to variations in motor and perceived competence and physical activity during childhood? (b) How do constructs and relationships change with increasing age and in transitions such as early to middle and late childhood? (c) How do theory and research on motor and psychosocial development translate to best practices for promoting youth physical activity? Questions cut across psychology subdisciplines within kinesiology-motor development, sport psychology, and motor learning/control. The call for integrating questions, theories, and methods across subdisciplines is not new in our field, as several scholars advocated for such an approach going back several decades.

\section{Historical Efforts Toward Integrating Psychology Subdisciplines Within Kinesiology}

Over 30 years ago, Mary Ann Roberton (1988) used the metaphor of a weaver's loom to encourage more frequent integration of ideas and methods in motor 
development, sport psychology, and motor learning/control. Such a "crossstitching" approach, she argued, would elevate our understanding of motor behavior and the processes underlying change across developmental periods. She identified four areas-research methods, levels of analysis, ideas or paradigms, and action systems - that could be targeted for integration. Each was accompanied by examples of how knowledge produced independently in the subdisciplines could be merged for a more comprehensive understanding of motor behavior and change over time (e.g., person-environment interaction). She concluded, "The weaver's loom is an appropriate analogy for the back and forth sharing of ideas that could enrich our mutual study" (p. 138).

Roberton (1988) highlighted Griffin and Keogh's (1982) model of movement confidence as an example of integrating action systems of motor development and sport psychology. According to the model, movement confidence (perceptions of adequacy in movement situations) is a consequence of movement competence (skillfulness in movement activities relative to task demands) and mediates the relationship between movement competence and participation behavior. Children who demonstrate skilled behavior will appraise abilities favorably and be motivated to continue in an activity, sustain effort, and perform at a higher level. Greater participation motivation should translate to improved motor skill competence, and the movement involvement cycle continues. A unique concept in the model is movement sensory experiences - anticipated desirable or undesirable movement sensations will affect self-confidence and whether a person seeks or avoids movement situations. ${ }^{2}$ The authors maintained that the movement involvement cycle will be a positive spiral for confident movers-resulting in greater participation motivation and continued motor skill improvement - and a negative spiral for unconfident movers. I highlight this example because Griffin and Keogh's (1982) ideas are remarkably similar to social psychological theories that posit relationships among domain-specific ability, perceived competence, and physical activity motivation (see Horn \& Newton, 2019; Weiss, 2019b). In fact, Griffin and Keogh stated that constructs and relationships in the movement confidence model were partially adopted from competence motivation and achievement goal theories (Harter, 1978; Nicholls, 1978). These theories are relevant for understanding the motor-perceived competence link and resultant physical activity behavior.

In a conceptual paper by Weiss and Bredemeier (1983), they proposed a developmental theoretical orientation for studying psychosocial and motor skill outcomes of youth sport participation. They highlighted developmental theories such as competence motivation theory (Harter, 1978, 1981) for building bridges between sport psychology and motor development. Duda (1987) published a companion paper that identified achievement goal theory (Nicholls, 1978, 1984) as another developmental orientation for studying children's involvement in sport. These theories have been instrumental in guiding scholarly inquiry on youth physical activity motivation (e.g., Horn \& Newton, 2019; Weiss \& Williams, 2004). In Developmental Sport and Exercise Psychology: A Lifespan Perspective (Weiss, 2004), chapters addressed theory and research on topics cutting across sport psychology, motor development, and motor learning. Chapters included Block, Griebenauw, and Brodeur's (2004) review of psychosocial factors and motor skill development among youth with disabilities, Horn's (2004) synthesis of developmental trends in perceived physical competence, and French and 
McPherson's (2004) research on developmental factors related to knowledge content and problem representation in motor skill acquisition. Given the developmental and integrated perspectives, it is surprising that none of the chapters in the book were cited in the motor development literature I reviewed.

In 1996, Malina argued for a biocultural perspective to motor skill development and sport participation, and he continued to advocate this approach for understanding variations in physical activity (Malina, 2008, 2014). His perspective acknowledges the interaction of biological, psychological, and sociocultural factors that explain differences in motor skills, physical activity, and sport participation, such as gender, physical maturity, opportunity sets, and ideologies of societies in which individuals are raised. For example, he notes that gender differences (favoring boys) in motor performance, sport skills, and physical activity levels are based on group averages, but biological maturity status is a moderating variable: early-maturing girls and late-maturing boys are less likely to be represented in samples of adolescent athletes (i.e., skilled performers). He suggests that coaches respond differently toward participants during the transition to adolescence based on maturity-related information and may help explain gender differences in motor skills and physical activity. These ideas are reinforced in the sport psychology literature on coaching behaviors (e.g., Horn, 2015; Horn, Lox, \& Labrador, 2015).

Historically, scholars have encouraged collaboration among subdisciplines where integration of theories, methods, and systems can achieve a better understanding of movement behavior. This makes sense but as Roberton (1988) implored, "I value the uniqueness of each area; so, I am proposing 'integration' but not 'obliteration'.... Each subdiscipline has much to contribute on its own; yet, each could learn from the other two areas" (p. 129). Motor development and sport psychology researchers share common interest in explaining relationships among motor and perceived competence and physical activity, making this a natural topic for collaboration. In the next section, I summarize motor development frameworks, metaphors, and models that describe age-related changes in motor skill competence and highlight the importance of fundamental motor skills for encouraging lifelong physical activity.

\section{Motor Development Frameworks, Metaphors, and Models}

Several frameworks depict age-related changes in movement competence and its relation to lifelong physical activity. Seefeldt's (1980) hierarchy of motor skills portrays sequential layers in developing motor abilities and skills as a function of age and task complexity. Reflexes during infancy are followed by fundamental motor skills (locomotor, object control) typically acquired in early childhood and are foundational for learning more complex skills needed for culturally specific games and sports. A proficiency barrier conveys that inability to master fundamental motor skills early in life leads to difficulty performing certain sport skills and lifetime activities.

Clark and Metcalfe's (2002) metaphor of a mountain of motor development represents a sequence of levels that individuals "climb" toward mastering motor 
skills over the lifespan. Motor patterns acquired during infancy are followed by fundamental motor skills typically learned from ages 1 to 7 years. Like Seefeldt, Clark proposes a proficiency barrier that may occur if children do not master the locomotor, object control, and coordinative skills that positively transfer to context-specific movements and skillfulness at the peak of the mountain. Climbing the mountain of motor development can be positively or negatively impacted by the environment, such as parent modeling of physical activity, and by individual characteristics such as perceived competence and motivation: "The two interact in determining the final outcome in 'mountain climbing"' (Clark, 2005, p. 38). A theme of person-environment interaction remains a thread of continuity in this essay because some models (e.g., Hulteen, Morgan, Barnett, Stodden, \& Lubans, 2018; Stodden et al., 2008) and studies do not explicitly include socioenvironmental influences of motor competence and physical activity. This omission limits an understanding of why differences emerge over the childhood and adolescent years and between boys and girls.

In a review of the last 50 years of motor development research, Clark (2017) presented the metaphor of a painter's "pentimento" for describing historical trends in philosophical and scientific approaches to motor development. Pentimento refers to a canvas comprising many layers that can be peeled back to view the layers beneath it. She noted that the deeper layers of maturational, normative/descriptive, process-oriented, and dynamical systems periods have evolved to adding two layers describing current motor development research-developmental neuroscience and public health. The public health perspective is relevant to the present discussion; developing fundamental motor and sport-specific skills during childhood provides a foundation for being physically active and acquiring health benefits over the lifespan.

Stemming from previous frameworks (Clark \& Metcalfe, 2002; Seefeldt, 1980), Stodden and his colleagues (2008) proposed a heuristic model specifying relationships among motor competence, perceived competence, physical activity, and health-related fitness, with directional pathways for early, middle, and late childhood. The model is complex with many direct, indirect, and bidirectional relationships. Nearly every study I reviewed examining relationships among two or more model constructs cited this article, often attributing empirical evidence to this citation rather than to primary data sources. I question some aspects regarding conceptual clarity to highlight the benefit of integrating knowledge from motor development and sport psychology to advance understanding of model relationships. First, Stodden et al. define motor competence as, “. . . proficiency in common FMS [fundamental motor skills] including object control and locomotor skill development" (p. 293). This is a narrower definition than others referring to motor competence as skillful performance in a variety of movement activities (Griffin \& Keogh, 1982; Malina, 2008). Moreover, Robinson et al. (2015) define motor competence even more broadly as motor proficiency, motor performance, fundamental movement skills, motor ability, and motor coordination.

A second conceptual issue is that Stodden et al.'s definition of motor competence as proficiency in fundamental motor skills means that perceived motor competence refers to an individual's self-appraisal of ability on locomotor and object control skills. This is inconsistent with how perceived competence is defined in social psychology research (Horn \& Newton, 2019; Weiss, Amorose, \& Kipp, 
2012), which is an individual's self-judgments of ability in a particular domain (e.g., academic, social, physical) or subdomain (e.g., math, peers, soccer). Research supports developmental theories (Eccles et al., 1983; Harter, 1978; Nicholls, 1978) specifying the relationship between perceived physical competence and activity choice, effort, and persistence (Weiss, 2019b). Perceived physical or sport competence is assessed starting in middle childhood because sport is a primary context for physical activity (Malina, 2008) and children as young as age 8 differentiate competence judgments across multiple domains (Horn, 2004). Stodden et al. state that theories, such as those by Harter and Eccles, “... provide a partial understanding of the underlying factors in physical activity, the focus of these models has been on the psychological dimension and children's perceptions of their motor competence, mastery attempts, and task persistence" (pp. 291-292, italics mine). They further say, "We ... suggest that an underlying mechanism in these models, not adequately addressed, is the notion of actual motor competence" (p. 292). It is important to point out these are competencebased theories, concerned with mastery of skills (i.e., actual competence), perceptions of competence, and motivated behavior. Because these theories were derived in mainstream psychology, they are not focused exclusively on motor competence or physical activity, but rather on competence and behavior in multiple achievement domains (Horn, 2004).

These theories have guided many studies in sport psychology, showing support for processes underlying youths' actual and perceived competence and physical activity motivation (Horn \& Newton, 2019; Weiss et al., 2012). Stodden et al. (2008) did not cite sport psychology studies supporting these competencebased theories for explaining relationships among actual and perceived competence and physical activity. Their hypothesis that "the relationship between motor skill competence and physical activity will strengthen over time" (p. 295) is not compatible with their model, as well as these theories, in which perceived competence mediates the relationship. This relationship will vary across the childhood years depending on how competence is construed, level of perceived competence, and which information sources are used to appraise motor abilities (Horn, 2004; Weiss \& Williams, 2004).

A third issue of conceptual clarity with Stodden et al.'s (2008) model is omission of socioenvironmental factors that influence motor and perceived competence and physical activity. They mention that "differences in experience" (e.g., immediate environment, parental influences) affect level of motor skill competence in early childhood, but they do not explain how this happens (i.e., underlying processes) or why this is not hypothesized for middle and late childhood and adolescence. Using a social psychological lens, competence-based theories (Eccles et al., 1983; Harter, 1978; Nicholls, 1978) accentuate the role of significant adults such as parents, teachers, and coaches in fostering domainspecific skills, perceived competence, and behaviors, such as effort and persistence, across childhood and adolescence (Horn \& Newton, 2019). This is supported in sport psychology, with mechanisms of influence including quality of feedback, interpersonal style, and motivational climate (Horn, 2019a; Horn \& Newton, 2019).

Stodden et al.'s (2008) article has influenced motor development research as evidenced by the number of studies that tested aspects of the model (see Catuzzo 
et al., 2016; Logan, Webster, Getchell, Pfeiffer, \& Robinson, 2015; Utesch, Bardid, Busch, \& Strauss, 2019). My intention in raising conceptual clarity is to identify areas that would benefit from integrating knowledge about youth engagement in physical activity, including developmental theories, conceptions of motor and perceived competence, and socioenvironmental variables as sources of physical activity behavior.

In summary, motor development frameworks represented by Seefeldt's (1980) hierarchy of motor skills and Clark and Metcalfe's (2002) mountain of motor development situate fundamental motor competence as the foundation for acquiring more complex context-specific and sport skills that enable lifelong physical activity. Stodden et al.'s (2008) conceptual model hypothesizes relationships among motor and perceived competence and physical activity during early, middle, and late childhood. I now transition to reviewing empirical research in motor development specific to these constructs and relationships.

\section{Motor Development Research on Motor and Perceived Competence and Physical Activity}

Early research efforts created a foundation for studying relationships among motor competence, perceived competence, and physical activity behavior. Griffin and Keogh's (1982) model of movement confidence contended that a child's appraisal of their ability to meet task demands mediates the relationship between motor competence and activity persistence. A few years after Griffin and Keogh's model was published, Beverly Ulrich (1987) extended their ideas and used Harter's $(1978)^{3}$ competence motivation theory as a guide to explore relationships among motor and perceived competence and sport participation among children in grades $\mathrm{K}$ to 4 . Ulrich developed items representing motor abilities (e.g., broad jump) and skills (e.g., soccer dribble) common to children in this age group, and added items to Harter's perceived physical competence scale to match motor competence items. Sport participation was documented by whether the child did or did not participate in at least one season during the past year. Findings supported links between motor and perceived competence and between motor competence and sport participation: children exhibiting stronger motor skills reported higher perceived physical competence and were more likely to participate in sport. Boys performed better on motor abilities and skills across grade and appraised physical competence more favorably than girls.

In a follow-up study, Ulrich and Ulrich (1997) assessed gender differences among children in grades $\mathrm{K}, 1$, and 2 on perceived competence of progressive motor skills: play (e.g., climbing), fundamental skills (e.g., throwing), and sportspecific skills (e.g., kicking a soccer ball). The set of play items was taken from Harter's scale and the authors generated fundamental motor and sport skill items relevant to children in this age group. Girls' competence perceptions were higher than boys for play items but lower for fundamental motor and sport skills. Boys reported similar perceptions of competence in all three motor skill sets across grade, whereas girls retained high perceptions for play but showed declines in perceived fundamental motor and sport skills from grades $K$ to 2 . Potential explanations for gender differences included beliefs about gender appropriateness 
of motor skills, variations in accuracy of perceptions (whether boys overestimated and girls underestimated motor competence), and behavioral expectations of girls and boys conveyed by parents, teachers, and coaches.

I intentionally elaborate on these studies to set up key issues in my subsequent review. First, Ulrich's studies raised the importance of conceptual clarity in measuring motor and perceived competence. An advancement has been developing fundamental motor and perceived motor competence measures for children in grades pre-K to 2 (see Barnett \& Goodway, 2018). A second issue is the need to differentiate level, accuracy, and sources of perceived competence. While Ulrich's studies focused on children's level of perceived competence (lower to higher scores), explanations for age and gender differences need to consider accuracy of perceived competence (whether perceptions are lower than, equivalent, or greater than actual competence) and sources of perceived competence such as effort, adult feedback, and peer comparison (Horn, 2004). Ulrich (1987) included grade K to 4 participants $(M$ age $=6-10$ yrs. $)$. Children in this age range are capable of responding with lower or higher ability ratings, but perceptions vary based on their ability to differentiate effort and ability and which sources are used to make selfability judgments (Horn, 2004). Studies exploring age and gender differences in accuracy and sources of perceived competence offer insight for explaining variations in level of perceived competence and its relationship to physical activity motivation (Horn, 2004).

Third, socioenvironmental factors are critical for explaining gender differences in motor and perceived competence and physical activity (Horn, 2018; Horn \& Newton, 2019). Parents, teachers, and coaches, as well as peers (classmates, teammates), are salient sources of competence information through feedback, approval, modeling, interpersonal style, and motivational climate. Moreover, gender beliefs and expectations are related to parents' and instructors' behaviors that influence children's skill improvement, perceived competence, and motivation (Fredricks \& Eccles, 2004; Horn, 2019b; Horn et al., 2015). It is not sufficient to say that boys and girls differ on motor and perceived competence and physical activity; we need to explain why differences emerge and identify strategies for removing disparities. Finally, Ulrich's studies raised insight on physical activity as a behavioral correlate of motor and perceived competence. In her studies, sport participation was assessed dichotomously as being a participant or nonparticipant. Perceived physical competence and sport participation were not significantly related. This finding is not surprising because children participating in sport primarily for social or fun reasons would not be expected to show a link between perceived physical competence and participation, but instead between perceived social competence or enjoyment and participation. Findings suggest we need to be purposeful in defining and assessing physical activity as choice, effort, and persistence (often used in structured contexts such as sport) or frequency, intensity, and duration (often used in unstructured contexts such as recreational activity).

Given these four key issues-measurement; level, accuracy, and sources of perceived competence; socioenvironmental factors; and physical activity assessment-I next review related literature on these topics. Sections are organized by measurement of motor and perceived competence, relationships among motor and perceived competence and physical activity, and intervention studies designed to promote fundamental motor competence and physical activity. 


\section{Measurement of Motor and Perceived Competence}

Barnett and Goodway (2018) guest edited a special issue of the Journal of Motor Learning and Development featuring studies developing measures of perceived motor competence to correspond with locomotor and object control skills assessed by Dale Ulrich's (2000) Test of Gross Motor Development. In sport psychology, Harter's age-appropriate measures include play skills for assessing perceived competence in grades $\mathrm{K}$ to 2 and sport skills in grades 3 to 8 (Horn, 2004). The child's and teacher's scales are structured in parallel form and interrater reliability of teachers' ratings help to attenuate expectation effects. Using teacher ratings as an index of competence is an alternative strategy in the absence of valid objective measures or opportunity to individually test children in studies with large sample sizes.

As mentioned, motor competence has been defined in varied ways such as locomotor and object control skills (Stodden et al., 2008), motor proficiency and coordination (Robinson et al., 2015), and skillful performance in movement activities (Malina, 2008). The broader definitions are inclusive of context-specific skills meaningful to children participating in youth sport or physical activity programs (Malina, 2008, Weiss, 2019b). Based on psychometric work with youth samples, I wonder whether perceived fundamental motor competence is appropriate for preschool through second-grade children and perceived physical (or sport) competence with children in grade 3 and older. It is important to choose motor and perceived competence measures that are conceptually consistent, developmentally appropriate, and context-relevant (e.g., motor skill program, youth sport).

\section{Relationships Among Motor Competence, Perceived Competence, and Physical Activity}

Robinson and her colleagues (2015) published a narrative review of studies testing Stodden et al.'s (2008) proposed relationships. Many studies revealed statistically significant associations between motor and perceived competence, between motor competence and physical activity, and perceived competence as a mediator of the motor competence-physical activity link. Small-to-medium effect sizes emerged, suggesting that other variables are important to include to account for unexplained variance. Few conclusions were drawn for hypothesized pathways for early, middle, and late childhood. Most studies were not guided by theory and used cross-sectional designs, suggesting correlational but not directional evidence of motor competence as an antecedent or consequence of perceived competence or physical activity. Robinson et al. mention social-cognitive theories that highlight perceived competence and its relation to actual competence and physical activity, but curiously they do not suggest theory-guided studies for future research testing model relationships. The authors also acknowledge Bronfenbrenner's (1977) social-ecological model: "There is a clear connection between the environmental context (e.g., aspects of the home, school, culture, psychological, and social influences) to MC [motor competence] . . . behaviors are adaptable properties promoted through complex interactions of biological, psychological, instructional, and environmental constraints that change across time" (p. 1275). However, discussion of unexplained variance in model relationships did not include potential 
socioenvironmental contributors. If we embrace an interactional approach to the role of motor competence in physical activity, then socioenvironmental processes at family, school, and community levels are prime candidates for inclusion in future research.

Since publication of Robinson et al.'s (2015) review, most studies still employ cross-sectional designs to examine relations among model constructs for preschool age (e.g., Webster, Martin, \& Staiano, 2019), middle and late childhood (e.g., Barnett, Lubans, Timperio, Salmon, \& Ridgers, 2018), and adolescence (e.g., McGrane, Powell, Belton, \& Issartel, 2018). Significant correlations with small-to-medium effect sizes emerge in some studies, whereas other studies show lack of support for relationships. Inconsistent results could be due to varied sampling methods, definitions of motor competence, and measures for perceived competence and physical activity. Many studies revealed that girls demonstrated lower fundamental motor skills and perceived competence than boys in childhood and adolescence (e.g., Barnett et al., 2018; Brian et al., 2018), but these findings were not accompanied by a discussion of processes or mechanisms of influence that might explain these differences. Social-cognitive theories and research in sport psychology highlight differential opportunities, feedback by significant adults, and stereotyped beliefs that potentially contribute to girls' lower motor and perceived competence compared to boys (Horn, 2018, 2019b).

Systematic reviews and meta-analyses provide an overview of the nature and strength of correlates of fundamental motor competence (e.g., Barnett et al., 2016; Logan et al., 2015; Utesch et al., 2019). Age, gender, perceived competence, and physical fitness show low-to-moderate relationships with fundamental motor competence. In some reviews only a small number of studies met the criteria for inclusion, suggesting that growing the knowledge base be given priority so that reviews include a more comprehensive set of studies on which to draw conclusions. Systematic reviews are the "flavor of the year" in many subdisciplines, but the same studies are often recycled across reviews making it appear the data base is larger than it is. Some reviews include a wide range of chronological ages and diverse measures for motor competence, perceived competence, and physical activity. Findings from systematic reviews offer a window for deriving future research questions, such as including omitted constructs (e.g., socioenvironmental variables) to push the boundaries of knowledge forward.

\section{Intervention Studies}

Theory-guided motor skill interventions show promise for determining the processes underlying motor competence and its relationship to perceived competence and physical activity (e.g., Palmer, Chinn, \& Robinson, 2017; Rudisill, 2016). In addition to being guided by developmental theory, these studies include longitudinal designs, comparison or control groups, retention tests, socioenvironmental factors, and manipulation checks for ensuring fidelity in delivering the intervention. These characteristics enable strong tests of the underlying factors that contribute to improved motor skill competence and physical activity levels in children. 
Mary Rudisill (2016) and her colleagues implement motor skill programs grounded in achievement goal theory with typically and atypically developing preschool, kindergarten, and elementary-age children. A mastery motivational climate places emphasis on aspects of group structure and teaching methods that promote task goal involvement among participants, in which competence is defined and evaluated in self-referenced terms such as personal mastery, effort, and enjoyment. Across many studies, children participating in a mastery climate program demonstrated superior motor skills, perceived competence, and physical activity behaviors compared to children in traditional physical education or free play conditions.

Leah Robinson's motor skill intervention, CHAMP (Children's Health Activity Motor Program), is implemented with preschool children in Head Start and physical education contexts (e.g., Palmer, Chinn, \& Robinson, 2019; Robinson, Palmer, Webster, Logan, \& Chinn, 2018; Robinson, Palmer, \& Meehan, 2017). This program is grounded in achievement goal theory with an emphasis on a mastery motivational climate to provide classroom structure, autonomy support, and feedback to improve motor skills. Over a systematic series of studies, children participating in the CHAMP intervention, compared to those in control groups (regular Head Start free play activities), showed greater improvement (with large effect sizes) in fundamental motor skills and moderate-to-vigorous physical activity.

Jacqueline Goodway and her colleagues implement theory-guided interventions with preschoolers, many who are developmentally delayed in motor skills (e.g., Altunsöz \& Goodway, 2016; Brian, Goodway, Logan, \& Sutherland, 2017; Robinson \& Goodway, 2009). Project SKIP (Successful Kinesthetic Instruction for Preschoolers) was designed based on dynamical and ecological systems theories, with learner, task, and environment factors integrated in lesson planning and delivery (see Altunsöz \& Goodway, 2016). Both teacher-directed and mastery climate approaches are used, with instruction focused on improving motor skills through demonstration, feedback, prompts, and task and environment modifications. In their studies, SKIP participants showed favorable gains on locomotor and object control skills compared to control groups (well-equipped free play conditions).

The theory-guided interventions reviewed in this section show strong design features and specify behavioral strategies that enhance children's engagement and persistence leading to improved motor skills, perceived competence, and physical activity. Such approaches integrate knowledge across subdisciplines and reveal strong impact and meaningful outcomes.

In sum, Ulrich's (1987, Ulrich \& Ulrich, 1997) early studies linking motor and perceived competence were followed by lines of research that advanced the knowledge base. This includes developing age-appropriate measures of motor and perceived competence; testing relationships among motor, psychological, and behavioral constructs; and conducting interventions to improve fundamental motor skills. Next, I review the social psychology literature on perceived competence and physical activity motivation to inform ways in which motor development and sport psychology scholars can integrate knowledge to advance research and practice. 


\section{Youth Physical Activity Through a Social Psychological Lens}

Social-cognitive theories have guided research revealing strong support for agerelated trends in level, accuracy, and sources of perceived competence, and relationships among socioenvironmental factors, perceived competence, and physical activity motivation. ${ }^{4}$ These theories are described superficially in Stodden et al. (2008) and dismissed as applicable for studying motor competence in relation to perceived competence and physical activity. Most studies exploring relationships in Stodden et al.'s model were atheoretical, limiting an understanding of the processes underlying behavior change, a critical definitional aspect of motor development. Moreover, few youth sport psychology studies were cited that pertain directly to model constructs and relationships. I would like to make the case that social-cognitive theories are well-suited for guiding inquiry on relationships among competence constructs and physical activity as well as for explaining age and gender differences (Horn \& Newton, 2019).

Developmental sport psychologists view physical activity ${ }^{5}$ using a motivational approach. Everybody knows that physical activity is important for attaining health benefits, but knowing has not translated to doing for youth around the world who are not meeting recommended guidelines (e.g., Tremblay et al., 2016). Children and adolescents do not participate in physical activity for health-related reasons like adults do. A social psychological perspective focuses on children's reasons for participating (motivational orientations) that relate to choice, effort, and persistence (motivated behavior). Youth often equate the term physical activity with sports, which is a primary context starting in middle childhood and even earlier (Malina, 2008). Given this overview of youth motivation and physical activity, I review literature on (a) competence-based theories; (b) theory-driven studies on youth physical activity motivation, including robust findings for parent, coach, and peer influence; and (c) translating motivation theory and research to evidence-based best practices.

\section{Competence-Based Theories of Youth Motivation}

Early descriptive studies (Weiss, 2013) revealed that youth participate in sports and physical activities to (a) develop and demonstrate physical competence (e.g., learn and improve skills), (b) attain social acceptance and approval (e.g., be with and make friends), and (c) experience enjoyment (e.g., have fun, be challenged). Thus, motor skill competence is not the only goal explaining participation-positive social and emotional experiences are also primary motives for involvement. These common participation motives led to adopting theories that highlight competence, social, and enjoyment components (Weiss, 2013). Three social-cognitivedevelopmental theories have been productive for expanding knowledge of youth physical activity: competence motivation theory (Harter, 1978, 1981), achievement goal theory (Nicholls, 1978, 1984), and expectancy-value theory (Eccles et al., 1983). Self-determination theory (Deci \& Ryan, 1985) is another socialcognitive framework for understanding predictors of physical activity motivation. Studies based on these theories yield consistent processes and mechanisms of influence explaining variations in youth physical activity (Horn \& Newton, 2019; 
Weiss et al., 2012). I briefly summarize each theory to highlight their utility for motor development research.

Competence motivation theory (Harter, 1978, 1981) asserts that children are motivated to have an effect on their environment; that is, to develop and demonstrate competence in achievement domains. Intrinsic interest in developing competence is influenced by the desire for challenge, curiosity, and joy. Successful mastery of skills (i.e., demonstrating competence), especially for optimal challenges, increases perceived competence and control, positive affect, and intrinsic motivation, leading to continued efforts to develop and demonstrate competence. Harter highlighted the role of significant others who respond to children's mastery attempts and performances through approval, modeling, and reinforcement, which impact children's perceived competence, enjoyment, and motivation. Perceived competence is consistently and strongly related to physical activity motivation and mediates the influence of actual competence (i.e., motor skill) and social influence on activity choice, effort, and persistence (Horn \& Newton, 2019). Age and gender differences in level, accuracy, and sources of perceived competence are observed over the childhood and adolescent years, and are influenced by developmental change in cognitive abilities and interactions with significant adults and peers (Horn, 2004).

Nicholls' (1978, 1984) achievement goal theory is also concerned with competence-individuals are motivated to demonstrate high ability and avoid demonstrating low ability. Competence, however, can be construed in task- or ego-involving ways. A child high in task involvement views competence in selfreferenced terms, such as effort and improvement, whereas a child high in ego involvement views competence in normative terms, such as peer comparison. Dweck's (1999) achievement goal perspective views conceptions of ability as a fixed mindset (an inherent trait) or growth mindset (modifiable through effort and practice). According to Nicholls (1984), young children with an undifferentiated conception of ability will be task-involved in activities (i.e., effort is the index of competence), whereas older youth with a mature conception of ability will exhibit some combination of task and ego involvement. The learning environment, known as the motivational climate (Ames, 1992), also influences a child's goal involvement and activity engagement. Climates created by instructors can be primarily task-involving (also called mastery climates) or ego-involving (also called performance climates). Teachers who create task-involving climates give feedback for personal improvement and provide students with choices, whereas ego-involving climates entail normative feedback and a direct instructional style. Benefits of a task-involving climate for enhancing actual and perceived competence and intrinsic motivation are supported in motor skill, physical education, and youth sport studies (Ennis, 2017; Horn \& Newton, 2019; Palmer et al., 2017).

Expectancy-value theory (Eccles et al., 1983) explains variations in achievement behaviors (i.e., domain-specific competence) as directly influenced by expectations of success (i.e., perceived competence) and subjective task value (importance placed on being successful in a domain). Indirect sources of influence on achievement behavior include socializers' beliefs and behaviors, gender and activity stereotypes, and past mastery experiences, among others. Eccles et al. (1983) document developmental trends for competence beliefs, such as declining 
levels across the childhood years and in educational transitions (e.g., elementary to middle school). Change in perceived competence is attributed to increased cognitive ability to integrate feedback from others, greater use of social comparison to judge competence, and a shift from task-involving to ego-involving forms of evaluation in achievement domains (e.g., school, sport). Gender differences emerged across domains in children as young as first grade, with girls reporting higher perceived competence than boys for reading but lower scores for math, fundamental motor skills (e.g., running, broad jump), and sports (Eccles \& Harold, 1991; Fredricks \& Eccles, 2004). Differences were explained by children's genderrole beliefs that corresponded with perceptions of their parents' and teachers' gender-based expectations and behaviors.

Finally, self-determination theory (Deci \& Ryan, 1985) is a framework for understanding variations in motivation, health, and well-being. The theory posits that individuals have three basic psychological needs-the need for competence (to feel capable in an activity), the need for autonomy (to experience activities out of choice), and the need for relatedness (to feel connected to others). Socioenvironmental factors that satisfy or hinder satisfaction of perceived competence, autonomy, and relatedness influence intrinsic and extrinsic motivational orientations, motivated behavior (effort, persistence), and physical and psychosocial well-being (e.g., self-esteem, health-related fitness). Examples of social factors include instructor and parent interpersonal style (e.g., autonomy-supportive v. controlling), quantity and quality of feedback, motivational climate (task- v. ego-involving), and friendship quality (Horn, 2019a; Weiss et al., 2012). Selfdetermination theory has been a popular approach for studying youth physical activity motivation, and is often paired with aspects of achievement goal theory (e.g., coach autonomy support and motivational climate as predictors of behavior and well-being).

In summary, developing and demonstrating competence is central to these four theories. They identify perceived competence as a primary individual difference variable and significant adults and peers as socioenvironmental influences of motivational orientations and activity choice, effort, and persistence. Positive affect or enjoyment is a correlate of behavior in all these theories. Thus, competence, social, and enjoyment motives for participation are captured in all approaches. Based on these qualities, the four theories are appropriate for exploring relationships among motor competence, perceived competence, and youth physical activity (Horn, 2018, 2019b). In addition to sport psychology, pedagogy scholars have also used these theories to investigate students' conceptions of ability, teacher behaviors, and motivational climate in relation to psychological and behavioral outcomes in physical education (e.g., Bryan \& Solmon, 2007; Chen, Sun, Dai, \& Griffin, 2017; Zhang, Solmon, \& Gu, 2012).

\section{Relationships Among Socioenvironmental Factors, Perceived Competence, and Physical Activity Motivation}

These four theories have guided research exploring relationships among social, psychological, and behavioral constructs (Weiss, 2019b). Significant others' beliefs and behaviors are strongly related to youths' perceived competence, enjoyment, motivational orientations (intrinsic v. extrinsic reasons), and physical 
activity behaviors (e.g., sustained participation). Parents, coaches/instructors, and peers provide opportunities for developing competence, enabling choice and voice, promoting feelings of relatedness, and experiencing enjoyment. Being physically active within a supportive climate that emphasizes personal mastery and enjoyment should, in turn, facilitate improvement of motor skill competence. In the following sections, I briefly summarize robust findings from theory-guided studies on parent, coach, and peer influence on youths' perceived competence and physical activity motivation.

Parents. In the last 20 years, studies rapidly multiplied on parents' beliefs and behaviors in relation to children's perceived competence, enjoyment, and physical activity motivation (Horn \& Horn, 2007; Weiss et al., 2012). Parents' activity beliefs and behaviors are often classified as providers of experience (e.g., sign-ups for a sport, transport to lessons, emotional support), interpreters of experience (e.g., conveying beliefs about child's competence, expressing value of physical activity), and role models (e.g., being physically active, coaching) (Fredricks \& Eccles, 2004). Children's perceptions of their parents' beliefs and behaviors are strongly linked to their own attitudes and participation. For example, children's perceptions of their parents' beliefs about their physical competence, rather than parent-reported beliefs, are more strongly related to children's self-judgments of ability and motivation. Children's perceived competence in an activity strongly predicts their enjoyment and participation behavior. Higher competence perceptions translate to continued involvement, whereas lower perceptions likely result in switching sports or activities (Weiss, 2013). A unique process grounded in expectancy-value theory is whether parents hold gender-stereotyped beliefs regarding their son's or daughter's involvement in certain activities (e.g., ice hockey for sons, figure skating for girls), and whether beliefs translate to behaviors such as differential opportunities, social support, and resources (Eccles \& Harold, 1991; Fredricks \& Eccles, 2004).

Coaches. Coaches positively impact youths' motor and perceived competence, enjoyment, and motivational orientations and behaviors (Horn, 2019a; Horn et al., 2015). Key coaching behaviors include (a) quantity and quality of instruction, (b) feedback patterns, (c) frequency and quality of coach-athlete interactions, (d) interpersonal style as autonomy-supportive or controlling, and (e) motivational climate. Coaches who provide contingent and appropriate praise for successful mastery attempts and mistake-contingent encouragement and instruction following unsuccessful performance are associated with youth who show improved skills and higher perceived competence, enjoyment, and intrinsic motivation (Horn et al., 2015). Youths' perceptions of greater coach autonomy support (e.g., afforded choices) translate to favorable psychological (e.g., perceived competence) and behavioral (e.g., effort) outcomes, including skill development and intrinsic interest (Horn, 2019a). By contrast, perceptions of a controlling style (e.g., overly critical feedback) are associated with lower perceived competence, autonomy, relatedness, and self-determined motivation, which may lead to discontinued involvement. A task-involving climate, in which coaches praise and give feedback for individual improvement rather than peer comparison, is associated with higher perceived competence, enjoyment, intrinsic motivation, and persistence (Horn \& Newton, 2019). Positive outcomes contribute to further developing physical skills 
and sustained participation. Opposite results apply for perceptions of an egoinvolving climate, especially for youth with lower perceptions of competence. In an atmosphere where social comparison is highlighted, low-confident children will be motivated to avoid demonstrating low ability and likely discontinue this activity.

Peers. One's peer group, including classmates, friends, and teammates is an important source of perceived competence and participation motivation, which intensifies in late childhood and adolescence (Smith, Mellano, \& Ullrich-French, 2019). Both peer acceptance and close friendship are salient aspects of peer relationships. Peer acceptance refers to the degree to which a child feels liked or accepted by members of their peer group. Youth identify being good at sports as important for being popular, and there is a strong link between physical competence and peer acceptance. Youth higher in perceived peer acceptance are motivated to continue participating to maintain friendships and they experience greater enjoyment of physical activity (Smith et al., 2019). Enjoying and continuing participation because of positive peer experiences should lead to further improvement of motor skills and interest in sustaining physical activity. Friendship refers to a close, dyadic, reciprocal relationship characterized by qualities such as similarity of interests and companionship (Smith et al., 2019). Other positive characteristics reported for best friendships include self-esteem enhancement, intimacy, loyalty, emotional support, help and guidance, and conflict resolution, whereas conflict is an occasional negative attribute. Having a close friendship in sport/physical activity along with greater positive qualities (e.g., companionship, loyalty) is strongly associated with higher perceived competence, positive affect, intrinsic motivation, and physical activity behavior (Weiss et al., 2012).

\section{Translating Motivation Theory and Research to Best Practices}

Findings based on the four social-cognitive theories reveal robust relationships among socioenvironmental factors (significant adults and peers), perceived competence, enjoyment, motivational orientations, and physical activity behavior. Findings are readily translated to evidence-based best practices for promoting youth physical activity (Horn, 2019b; Stuntz \& Weiss, 2010). Supportive social environments, notably the attitudes, beliefs, and behaviors of significant adults and peers, positively impact physical activity behavior through opportunities for developing motor skill competence and enhancing feelings of competence, autonomy, relatedness, and enjoyment. Mechanisms of social influence include providing optimally challenging activities, positive and informational feedback, an autonomy-supportive style, and a mastery motivational climate. Improved motor competence and positive psychosocial attributes contribute to self-determined motivation for being physically active that, in turn, predicts physical activity behavior (choice, effort, persistence). Greater physical activity levels promote opportunities for further developing motor skill competence and achieving physical, social, and psychological health benefits. Horn (2019b) accentuates the need to eliminate gendered parenting and instructional practices that can jeopardize youth from experiencing the benefits of motor skill development, perceived competence, and physical activity motivation. The collective of these evidence-based practices connect motor and perceived competence and physical activity. 
In summary, social-cognitive theories show utility for investigating competence-related constructs and youth physical activity. Robust findings point to significant adult and peer influence on physical activity motivation through feedback patterns, role modeling, social approval, interpersonal style, and motivational climate. My review of motor development and sport psychology research reveals common questions yet different approaches to studying motor and perceived competence and physical activity. In the final section of my essay, I recommend several collaborative research directions to increase scholarly impact.

\section{Toward an Integrated Approach to Motor Development and Sport Psychology}

After immersing myself in the motor development literature and summarizing related content in youth sport psychology, it is understandable why our subdisciplines have sparingly cited research or integrated knowledge from the other subdiscipline. The time, effort, and energy involved in reading massive amounts of literature on a particular topic can be daunting. This necessarily points to the need for more collaboration between scholars from complementary areas of expertise to fully understand common topics of interest. This also reinforces the goals of the I-MDRC to join researchers from various backgrounds, share ideas about developmental research agendas, and develop strategies to increase scholarly impact through meaningful collaborations. Now that I have separately examined, albeit briefly, the related literatures in motor development and sport psychology, I turn my efforts to how we can collaborate to expand knowledge and reach in promoting children's physical activity. I recommend five ways for integrating knowledge: (1) applying social psychological theory to guide research questions, (2) using more longitudinal designs, (3) using a variety of quantitative and qualitative methods, (4) designing studies on physical literacy, and (5) employing a positive youth development (PYD) approach for improving motor and socialemotional skills.

First, we can collaborate by conducting more theory-driven studies that include competence, social, and affective components of physical activity motivation. This could include any of the social-cognitive theories discussed, among others (Horn \& Newton, 2019; Weiss, 2019b). These theories are strongly supported, offer testable hypotheses for relationships among actual ability, perceived competence, and behavioral outcomes, and propose variables that mediate or moderate relationships (e.g., age/cognitive maturity, gender). Consistent with bioecological human development models, social-cognitive theories include socioenvironmental factors such as how the beliefs and behaviors of important adults and peers influence youths' cognitions (e.g., perceived competence, motivational orientation) and physical activity behavior (e.g., motor performance, persistence) (Horn, 2018; Horn \& Newton, 2019). Eccles et al.'s (1983) expectancy-value theory has been beneficial for identifying socioenvironmental factors that explain gender differences in actual and perceived competence, value toward physical activity, and participation behavior. Many motor development studies noted that girls performed more poorly than boys on motor skills and had lower ability beliefs. To go beyond describing differences, socioenvironmental factors help 
explain why gender differences emerge (Horn, 2004, 2018). Socioenvironmental variables are not explicitly included in motor development models (e.g., Hulteen et al., 2018; Stodden et al., 2008) and most studies; including them would honor the interactional approach to human development advocated by ecological systems models and social psychological theories, and assist in accounting for the unexplained variance in studies investigating sources of physical activity behavior and health-related outcomes.

There are many avenues for expanding research on socioenvironmental factors and children's motor and psychosocial development. For example, intervention studies conducted in preschool settings revealed better motor skill improvement for mastery climate compared to free play conditions (e.g., Brian et al., 2017). According to achievement goal theory, 4-year-olds are naturally task-involved because they equate ability with effort, possibly explaining why comparison groups receiving direct instruction showed similar motor skill improvements to those exposed to a mastery climate. Mastery climate interventions with children in middle and late childhood would be of interest, since these children differentiate effort and ability as causes of successful performance, use coach feedback and peer comparison for judging physical competence, and respond to supportive environments that satisfy needs for competence, autonomy, and relatedness.

An excellent example of integrating motor behavior and sport psychology theories is the social-cognitive-affective-motor perspective on motor behavior conceived by Gabriele Wulf, a motor learning scholar, and Rebecca Lewthwaite, a sport psychology scholar (Lewthwaite \& Wulf, 2010). A visual (i.e., Venn diagram) depicts overlapping circles with the motor component (learning, control, and performance) in the center, surrounded by social (norms, culture, stereotypes), cognitive (knowledge, thoughts, attention), and affective (emotions, self-regulation) processes that influence, and are influenced by, motor behavior. In calling for this perspective Lewthwaite and Wulf (2010) state, "While motor learning researchers have long considered cognitive influences on learning, most have largely ignored—or not yet realized-the motivational (e.g., social-cognitive and affective) impact of the practice variables under investigation" (p. 2). The authors proposed the OPTIMAL theory of motor learning (Optimizing Performance through Intrinsic Motivation and Attention to Learning) to account for the social-cognitive-affective-motor nature of motor behavior (Wulf \& Lewthwaite, 2016). The theory integrates aspects of theories of motivation (e.g., performance expectancies, conceptions of ability, autonomy support) and attentional focus to optimize movement effectiveness. In one study, 10-year-old girls in an autonomy-supportive condition performed better than a control group on a sequence of ballet movements, as well as having higher expectancies, positive affect, and positive thoughts during practice (Lemos, Wulf, Lewthwaite, \& Chiviacowsky, 2017).

A second way of integrating knowledge is shifting from primarily crosssectional to more longitudinal designs to assess change in motor behavior over time and the processes that underlie change (e.g., socioenvironmental factors). The majority of studies testing relationships in Stodden et al.'s (2008) model are characterized by correlational designs, and many studies replicated others with different age groups or measures of perceived competence. One exception was a 
longitudinal study by Barnett, Morgan, van Beurden, and Beard (2008) guided by Harter's (1978) competence motivation theory, where elementary-age students were again assessed as adolescents to examine the relationship between object control skill and physical activity (and fitness) with perceived sport competence as a mediator. The mediation model was a good fit for boys and girls and for physical activity and fitness. The authors concluded, "A key strategy to promote adolescent physical activity and cardiorespiratory fitness in community and school settings should be to improve perceptions of sports competence especially by targeting object control motor skill development in childhood. Teachers should be encouraged to teach motor skills using a mastery learning environment where the child is able to succeed and is encouraged to personally improve which can lead to higher levels of enjoyment and greater levels of perceived competence" (p. 10). This quote is at the heart of justifying motor skill development and physical activity through a social psychological lens. In social psychology, Kirsten Davison and her colleagues have similarly conducted theory-driven, longitudinal studies to explore relationships between perceived competence and physical activity from middle childhood to adolescence, revealing moderating and mediating effects of biological maturity status and psychological and socioenvironmental factors (e.g., Davison, Downs, \& Birch, 2006; Davison \& Jago, 2009; Davison, Werder, Trost, Baker, \& Birch, 2007).

Sport specialization is a hot topic suitable for longitudinal, cross-disciplinary research. Scholars in motor development (Goodway \& Robinson, 2015), sport psychology (Horn, 2015), and motor learning (Anderson \& Mayo, 2015) reviewed the benefits and downsides of sport specialization from their disciplinary perspective. Sport sampling v. sport specialization approaches were discussed based on biological maturation, fundamental motor competence, deliberate practice, specificity of learning, self-perceptions, motivational orientations, and socioenvironmental influences. The authors from all three subdisciplines concluded that early diversification of motor and sport skill participation is the preferable approach for positive transfer to specialization at older ages, if desired, and the ability to be physically active for a lifetime in traditional and nontraditional sports. The longterm effects of sport specialization are currently inferred from cross-sectional studies (e.g., comparing specializers v. non-specializers on burnout) or extrapolated from scientific knowledge on biological, physical, social, and psychological correlates of intensive training. Theory-guided, cross-disciplinary studies using longitudinal designs can contribute to making informed conclusions about the impact of sport specialization on long-term participation, physical activity, and health.

Third, a mixed-methods approach that employs a variety of quantitative and qualitative methods is another means by which motor development and sport psychology scholars can join forces. The motor development studies I reviewed primarily assessed fundamental motor skills using the TGMD and perceived competence with pictorial and paper-and-pencil measures. Most youth sport psychology research has been conducted with 8-year and older youth using valid and age-appropriate quantitative and qualitative methods. Both methods are beneficial when studying young children, who have limited cognitive skills in attention, memory, and verbal ability. I am reminded of a study based on my experience as director of CSSP. I continuously encountered children who 
avoided dressing for swim lessons or who observably showed tentativeness in the water. I designed an intervention to study the effect of peer models on young children's swim skills, self-efficacy, and fear (Weiss, McCullagh, Smith, \& Berlant, 1998). Children ( $M$ age $=6$ yrs. $)$ identified as fearful of the water were assigned to peer-mastery, peer-coping, or control conditions. Reliably assessing outcome variables posed a challenge, so we used mixed methods including videotaping of swim skills, a smiley-face measure of self-efficacy, instructor ratings of fear, field notes documenting instructor-child interactions, and post-intervention questions. A combination of quantitative (skill ratings, questionnaire items) and qualitative (field notes, open-ended questions) methods revealed insights that neither method alone would have achieved. We can collaborate by sharing multiple methods to gather data on motor skills, psychosocial variables, and physical activity behavior, including surveys, interviews, field observations, journaling, checklists, motor skill outcomes, and kinematics/ kinetics of motor skills.

Sport psychology studies have also benefited from methods to assess physical maturity as a control variable in testing relationships among variables or in comparing pre- and post-pubertal participants (e.g., Cumming et al., 2011; Davison et al., 2007; Smith, 1999). Malina's $(2008,2014)$ biocultural perspective points to variations among boys' and girls' motor skill development, sport participation, and physical activity as a function of biological maturity status, and he identifies biological maturation effects on physical activity as mediated by self-perceptions and social interactions as a "top 10" research question. Horn (2015; Horn et al., 2015) elaborates on the psychosocial factors related to early and late maturing boys and girls, such as coaches' differential skill instruction and performance feedback that contributes to, and even predicts, psychological, motivational, and participation outcomes. Theory-guided studies show that physical maturity is a moderating variable in the relationship among model constructs. For example, Smith (1999) used competence motivation theory to examine relationships among peer influence, perceived competence, positive affect, and physical activity motivation among middle school students. Boys advanced in physical maturity reported more positive self-perceptions, affect, and physical activity motivation than later-maturing boys; whereas, for girls maturity status was not significant (most were post-pubertal). Considering biological maturity status in studies of youth in late childhood and adolescence can enhance an understanding of variations in motor and perceived competence and physical activity participation.

Physical literacy is a fourth area suitable for collaboration, defined as the ability, confidence, and desire to be physically active for life (Glynn \& Hilton, 2016). These authors refer to ability as competence in fundamental motor skills and fitness level to enable participation in physical activities; confidence as belief in one's ability to play and enjoy physical activities; and desire as the intrinsic interest and motivation to be physically active. Socioenvironmental factors including teaching of motor skills, support and encouragement by adults and peers, and enjoyable experiences are named as processes by which competence, confidence, and the desire to be physically active (i.e., physical literacy) emerge. The italicized words (competence, confidence, desire) defining physical literacy characterize exactly what I have been discussing in this essay, specifically years 
of research on motor and perceived competence and physical activity motivation. And 13 years ago, Clark (2007) stated, "Teaching motor skills is not mutually exclusive with children being physically active. Indeed, if children do not feel a sense of efficacy regarding their motor skills, they are less likely to participate in physical activities as they grow older ... physical educators need to recognize the importance of motor literacy for a lifetime of physical activity" (p. 43). Thus, it is curious that physical literacy is (re)emerging as a new approach in the public health and physical education pedagogy literatures (e.g., Cairney, Dudley, Kwan, Bulten, \& Kriellaars, 2019; Chen \& Sun, 2015; Dudley, Cairney, \& Goodway, 2019; Durden-Myers \& Whitehead, 2018). Clearly, this is a suitable topic awaiting collaboration among motor development, sport psychology, and pedagogy researchers.

A final area conducive for collaboration is adopting a positive youth development (PYD) approach for promoting physical and psychosocial competencies through participation in physical activity contexts (Weiss, 2019a). PYD embraces a philosophy that all children and adolescents have the potential to grow and develop socially, psychologically, and behaviorally when afforded opportunities to learn important life skills in family, school, and community settings (Eccles \& Gootman, 2002; Lerner, Lerner, Almerigi, Theokas, \& Phelps, 2005). The PYD framework is grounded within ecological systems theories that highlight developmental outcomes as a result of the interaction between individuals (attitudes, beliefs, behaviors) and their social, environmental, and cultural contexts (e.g., Lerner et al., 2005). Social-contextual features of effective youth development programs include opportunities for skill building (physical, social, emotional), appropriate structure (adult guidance and monitoring), supportive relationships with adults and peers, opportunities to belong (a social environment that appreciates individual differences), physical and psychological safety (health-promoting facilities and practices), and valuing of individual expression and improvement (Eccles \& Gootman, 2002). Because the PYD framework was conceived by developmental psychologists, emphasis was on social, emotional, and behavioral competencies in home and school domains. Importantly, developmental sport psychologists added motor skill competence, movement literacy, and sport-specific skills as critical life skills that enable a lifetime of physical activity (Weiss \& Wiese-Bjornstal, 2009).

Over the last decade, the PYD framework has guided studies on life skills learning and psychosocial outcomes within physical activity contexts, including school physical education, out-of-school-time motor skill programs, and organized youth sport (Weiss, 2011; Weiss et al., 2019a). Effective physical activity-based PYD programs (PA-PYD) include an intentional curriculum of skill-building opportunities, trained instructors to deliver the curriculum with fidelity, lessons taught within a mastery motivational climate, and an emphasis on caring and supportive adult and peer relationships (Weiss, 2019a). These PA-PYD programs show positive effects on physical competence, self-confidence, social responsibility, physical activity, and life skills such as managing emotions, resolving conflicts, and helping others (e.g., Martinek \& Hellison, 2016; Weiss, Kipp, Phillips Reichter, Espinoza, \& Bolter, 2019). School-based and after-school physical activity programs serving preschoolers to adolescents are seeking our advice on creating curricula, training instructors, and optimizing motor skill and social-emotional 
learning, making PYD a natural topic for collaboration among motor development and sport psychology researchers.

\section{Concluding Remarks}

This essay transformed into a deeper introspection on integrating subdisciplines than when I gave my keynote at the I-MDRC conference in Verona, Italy, in 2019. The intellectual challenge has been fulfilling and I strived to be critical yet constructive in reviewing the literature and offering ideas to increase scholarly impact by developing meaningful collaborations. Ecological systems models and social-cognitive theories reinforce the value of an integrated perspective to the study of motor skill and psychosocial development through physical activity. I agree with Roberton (1988) — “integration but not obliteration"-but many opportunities await us for interweaving ideas for enriching our mutual study of youth development in physical activity contexts. I am hopeful that the theme of motor skill development and physical activity through a social psychological lens has translated to provocative ideas for integrating theories, designs, methods, and topics that capture our common interest. The theme also brings me back full circle to my foundational experiences as a youth sport coach, as a doctoral student learning the benefits of integrating subdisciplines, and as a director of a children's motor skill development program. I am very excited to see what the future holds through mutual partnerships to advance research and professional practice on motor skill and perceived competence as contributors to physical activity across the lifespan.

\section{Notes}

1. The ideas in this paper are based on my invited keynote at the I-MDRC conference in Verona, Italy, September, 2019.

2. This concept resonates with my experiences directing CSSP — children who were competent but fearful in swimming exhibited low confidence and avoided participating, which led to declines in skill development.

3. It is not surprising that Susan Harter made an impact on motor development and sport psychology research. As a keynote speaker at the 1980 NASPSPA meeting, she applied competence motivation theory to children's sport motivation. Ulrich (1987) cited Harter's (1981) publication based on her keynote presentation at that conference.

4. I elected to cite major review papers and book chapters that describe theories in detail and summarize a large body of knowledge based on these theories. Readers are encouraged to access original sources for further information.

5. I use physical activity as an umbrella term to include many youth contexts: structured such as motor skill programs, organized sport, and physical education; and unstructured such as play and recreational activity.

\section{Acknowledgments}

I am grateful to Thelma Horn and Jane Clark for their helpful comments and suggestions on an earlier version of this paper. 


\section{References}

Altunsöz, I., \& Goodway, J.D. (2016). SKIPing to motor competence: the influence of project successful kinesthetic instruction for preschoolers on motor competence of disadvantaged preschoolers. Physical Education and Sport Pedagogy, 21(4), 366-385. doi:10.1080/17408989.2015.1017453

Ames, C. (1992). Achievement goals, motivational climate, and motivational processes. In G.C. Roberts (Ed.), Motivation in sport and exercise (pp. 161-176). Champaign, IL: Human Kinetics.

Anderson, D.I., \& Mayo, A.M. (2015). A skill acquisition perspective on early specialization in sport. Kinesiology Review, 4(3), 230-247. doi:10.1123/kr.2015-0026

Barnett, L.M., \& Goodway, J.D. (2018). Perceptions of movement competence in children and adolescents from different cultures and countries. Journal of Motor Learning and Development, 6(Suppl. 2), S1683-S188. doi:10.1123/jmld.2018-0018

Barnett, L M., Lai, S.K., Veldman, S.L.C., Hardy, L.L., Cliff, D.P., Morgan, P.J., . . Okely, A.D. (2016). Correlates of gross motor competence in children and adolescents: A systematic review and meta-analysis. Sports Medicine, 46(11), 1663-1688. PubMed ID: 26894274 doi:10.1007/s40279-016-0495-z

Barnett, L.M., Lubans, D.R., Timperio, A., Salmon, J., \& Ridgers, N.D. (2018). What is the contribution of actual motor skill, fitness, and physical activity to children's selfperception of motor competence? Journal of Motor Learning and Development, 6(Suppl. 2), S461-S473. doi:10.1123/jmld.2016-0076

Barnett, L.M., Morgan, P.J., van Beurden, E., \& Beard, J.R. (2008). Perceived sports competence mediates the relationship between childhood motor skill proficiency and adolescent physical activity and fitness: a longitudinal assessment. International Journal of Behavioral Nutrition and Physical Activity, 5(1), 40. PubMed ID: 18687148 doi:10.1186/1479-5868-5-40

Block, M.E., Griebenauw, L-M, \& Brodeur, S. (2004). Psychosocial factors and disability: Effects of physical activity and sport. In M.R. Weiss (Ed.), Developmental Sport and Exercise psychology (pp. 425-451). Morgantown, WV: Fitness Information Technology.

Brian, A., Bardid, F., Barnett, L.M., Deconinck, F.J.A., Lenoir, M., \& Goodway, J.D. (2018). Actual and perceived motor competence levels of Belgian and United States preschool children. Journal of Motor Learning and Development, 6(Suppl. 2), S320S336. doi:10.1123/jmld.2016-0071

Brian, A., Goodway, J.D., Logan, J.A., \& Sutherland, S. (2017). SKIPing with teachers: an early years motor skill intervention. Physical Education and Sport Pedagogy, 22(3), 270-282. doi:10.1080/17408989.2016.1176133

Bronfenbrenner, U. (1977). Toward an experimental ecology of human development. American Psychologist, 32(7), 513-531. doi:10.1037/0003-066X.32.7.513

Bryan, C.L., \& Solmon, M.A. (2007). Self-determination in physical education: Designing class environments to promote active lifestyles. Journal of Teaching in Physical Education, 26(3), 260-278. doi:10.1123/jtpe.26.3.260

Cairney, J., Dudley, D., Kwan, M., Bulten, R., \& Kriellaars, D. (2019). Physical literacy, physical activity and health: Toward an evidence-informed conceptual model. Sports Medicine, 49(3), 371-383. PubMed ID: 30747375 doi:10.1007/s40279-019-01063-3

Catuzzo, M.T., Henrique, R.S., Ré, A.H.N., de Oliveira, I.S., Melo, B.M., de Sousa Moura, M., ... Stodden, D. (2016). Motor competence and health related physical fitness in youth: A systematic review. Journal of Science and Medicine in Sport, 19(2), 123-129. PubMed ID: 25554655 doi:10.1016/j.jsams.2014.12.004

Chen, A., \& Sun, H. (2015). A great leap of faith: Editorial for JSHS special issue on physical literacy. Journal of Sport and Health Science, 4(2), 105-107. doi:10.1016/j. jshs.2015.04.002 
Chen, H., Sun, H., Dai, J., \& Griffin, M. (2017). Relationships among middle school students' expectancy beliefs, task values, and health-related fitness performance. Journal of Teaching in Physical Education, 36(1), 40-49. doi:10.1123/jtpe.2016-0073

Clark, J.E. (2005). From the beginning: A developmental perspective on movement and mobility. Quest, 57(1), 37-45. doi:10.1080/00336297.2005.10491841

Clark, J.E. (2007). On the problem of motor skill development. Journal of Health, Physical Education, Recreation, and Dance, 78(5), 39-44. doi:10.1080/07303084.2007.10598023

Clark, J.E. (2017). Pentimento: A 21st century view on the canvas of motor development. Kinesiology Review, 6(3), 232-239. doi:10.1123/kr.2017-0020

Clark, J.E., \& Metcalfe, J.S. (2002). The mountain of motor development: A metaphor. In J.E. Clark \& J. Humphrey (Eds.), Motor development: Research and reviews (Vol. 2, pp. 163-190). Reston, VA: NASPE Publications.

Clark, J.E., \& Whitall, J. (1989). What is motor development? The lessons of history. Quest, 41(3), 183-202. doi:10.1080/00336297.1989.10483969

Cumming, S.P., Standage, M., Loney, T., Gammon, C., Neville, H., Sherar, L.B., \& Malina, R.M. (2011). The mediating role of physical self-concept on relations between biological maturity status and physical activity in adolescent females. Journal of Adolescence, 34(3), 465-473. PubMed ID: 20655102 doi:10.1016/j.adolescence.2010. 06.006

Davison, K.K., Downs, D., \& Birch, L.L. (2006). Pathways linking perceived athletic competence and parental support at age 9 years to girls' physical activity at age 11 years. Research Quarterly for Exercise and Sport, 77(1), 23-31. PubMed ID: 16646349 doi:10.1080/02701367.2006.10599328

Davison, K.K., \& Jago, R. (2009). Change in parent and peer support across ages 9 to $15 \mathrm{yr}$ and adolescent girls' physical activity. Medicine \& Science in Sports \& Exercise, 41(9), 1816-1825. PubMed ID: 19657287 doi:10.1249/MSS.0b013e3181a278e2

Davison, K.K., Werder, J.L., Trost, S.G., Baker, B.L., \& Birch, L.L. (2007). Why are early maturing girls less active? Links between pubertal development, psychological wellbeing, and physical activity among girls at ages 11 and 13. Social Sciences \& Medicine, 64(12), 2391-2404. doi:10.1016/j.socscimed.2007.02.033

Deci, E.L., \& Ryan, R.M. (1985). Intrinsic motivation and self-determination in human behavior. New York, NY: Plenum.

Duda, J.L. (1987). Toward a developmental theory of children's motivation in sport. Journal of Sport Psychology, 9(2), 130-145. doi:10.1123/jsp.9.2.130

Dudley, D., Cairney, J., \& Goodway, J. (2019). Special issue on physical literacy: Evidence and intervention. Journal of Teaching in Physical Education, 38(2), 77-78. doi:10. 1123/jtpe.2019-0020

Durden-Myers, E.J., \& Whitehead, M.E. (2018). Operationalizing physical literacy: Special issue editorial. Journal of Teaching in Physical Education, 37(3), 234-236. doi:10. 1123/jtpe.2018-0130

Dweck, C.S. (1999). Self-theories: Their role in motivation, personality, and development. Philadelphia, PA: Taylor \& Francis.

Eccles, J.S., Adler, T.E., Futterman, R., Goff, S.B., Kaczala, C.M., Meece, J.L., \& Midgley, C. (1983). Expectancies, values, and academic behaviors. In J.T. Spence (Ed.), Achievement and achievement motivation (pp. 75-146). San Francisco, CA: W.H. Freeman.

Eccles, J.S., \& Gootman, J.A. (2002). Features of positive developmental settings. In J.S. Eccles \& J.A. Gootman (Eds.), Community programs to promote youth development (pp. 86-118). Washington, DC: National Academy Press.

Eccles, J.S., \& Harold, R.D. (1991). Gender differences in sport involvement: Applying the Eccles' expectancy-value model. Journal of Applied Sport Psychology, 3(1), 7-35. doi:10.1080/10413209108406432 
Ennis, C.D. (2017). Educating students for a lifetime of physical activity: Enhancing mindfulness, motivation, and meaning. Research Quarterly for Exercise and Sport, 88(3), 241-250. PubMed ID: 28742426 doi:10.1080/02701367.2017.1342495

Fredricks, J.A., \& Eccles, J.S. (2004). Parental influences on youth involvement in sports. In M.R. Weiss (Ed.), Developmental sport and exercise psychology: A lifespan perspective (pp. 145-164). Morgantown, WV: Fitness Information Technology.

French, K.E., \& McPherson, S.L. (2004). Development of expertise in sport. In M.R. Weiss (Ed.), Developmental sport and exercise psychology: A lifespan perspective (pp. 403423). Morgantown, WV: Fitness Information Technology.

Glynn, D., \& Hilton, C. (2016). Developing physical literacy in community settings. Elevate Health, 18(3), 1-12.

Goodway, J.D., \& Robinson, L.E. (2015). Developmental trajectories in early sport specialization: A case for early sampling from a physical growth and motor development perspective. Kinesiology Review, 4(3), 267-278. doi:10.1123/kr.2015-0028

Griffin, N.S., \& Keogh, J.F. (1982). A model of movement confidence. In J.A.S. Kelso \& J.E. Clark (Eds.), The development of movement control and co-ordination (pp. 213236). New York, NY: Wiley.

Harter, S. (1978). Effectance motivation reconsidered: Toward a developmental model. Human Development, 21(1), 34-64. doi:10.1159/000271574

Harter, S. (1981). The development of competence motivation in the mastery of cognitive and physical skills: Is there still a place for joy? In G.C. Roberts \& D.M. Landers (Eds.), Psychology of motor behavior and sport- 1980 (pp. 3-29). Champaign, IL: Human Kinetics.

Horn, T.S. (2004). Developmental perspectives on self-perceptions in children and adolescents. In M.R. Weiss (Ed.), Developmental sport and exercise psychology: A lifespan perspective (pp. 101-143). Morgantown, WV: Fitness Information Technology.

Horn, T.S. (2015). Social psychological and developmental perspectives on early sport specialization. Kinesiology Review, 4(3), 248-266. doi:10.1123/kr.2015-0025

Horn, T.S. (2018). Perceptions of movement competence in children and adolescents from different cultures and countries: A commentary. Journal of Motor Learning and Development, 6(Suppl. 2), S474-S480. doi:10.1123/jmld.2018-0018

Horn, T.S. (2019a). Examining the impact of coaches' feedback patterns on the psychosocial well-being of youth sport athletes. Kinesiology Review, 8(3), 244-251. doi:10.1123/kr. 2019-0017

Horn, T.S. (2019b). Learning to take joy and perceive competence in physical movement: Origins in early childhood. Kinesiology Review, 8(1), 40-47. doi:10.1123/kr.20180059

Horn, T.S., \& Horn, J.L. (2007). Family influences on children's sport and physical activity participation, behavior, and psychosocial responses. In G. Tenenbaum and R.C. Eklund (Eds.), Handbook of sport psychology (3rd ed., pp. 685-711). Hoboken, NJ: Wiley.

Horn, T.S., Lox, C.L., \& Labrador, F. (2015). The self-fulfilling prophecy theory: When coaches' expectations become reality. In J.M. Williams \& V. Krane (Eds.), Applied sport psychology: Personal growth to peak performance (7th ed., pp. 78-100). New York, NY: McGraw Hill.

Horn, T.S., \& Newton, J.L. (2019). Developmentally based perspectives on motivated behavior in sport and physical activity contexts. In T.S. Horn and A.L. Smith (Eds.), Advances in sport and exercise psychology (4th ed., pp. 313-331). Champaign, IL: Human Kinetics.

Hulteen, R.M., Morgan, P.J., Barnett, L.M., Stodden, D.F., \& Lubans, D.R. (2018). Development of foundational movement skills: A conceptual model for physical activity across the lifespan. Sports Medicine, 48(7), 1533-1540. PubMed ID: 29524160 doi:10.1007/s40279-018-0892-6 
Lemos, A., Wulf, G., Lewthwaite, R., \& Chiviacowsky, S. (2017). Autonomy support enhances performance expectancies, positive affect, and motor learning. Psychology of Sport and Exercise, 31, 28-34. doi:10.1016/j.psychsport.2017.03.009

Lerner, R.M., Lerner, J.V., Almerigi, J.B., Theokas, C., Phelps, E., (2005). Positive youth development, participation in community youth development programs, and community contributions of fifth-grade adolescents: Findings from the first wave of the 4-H study of positive youth development. Journal of Early Adolescence, 25(1), 17-71. doi: $10.1177 / 0272431604272461$

Lewthwaite, R., \& Wulf, G. (2010). Grand challenge for movement science and sport psychology: embracing the social-cognitive-affective-motor nature of motor behavior. Frontiers in Psychology, 1, 42. PubMed ID: 21833211 doi:10.3389/fpsyg.2010. 00042

Logan, S.W., Webster, E.K., Getchell, N., Pfeiffer, K.A., \& Robinson, L.E. (2015). Relationship between fundamental motor skill competence and physical activity during childhood and adolescence: A systematic review. Kinesiology Review, 4(4), 416-426. doi:10.1123/kr.2013-0012

Malina, R.M. (1996). The young athlete: Biological growth and maturation in a biocultural context. In F.L. Smoll \& R.E. Smith (Eds.), Children and youth in sport: A biopsychosocial perspective (pp. 161-186). Dubuque, IA: Brown \& Benchmark Publishers.

Malina, R.M. (2008). Biocultural factors in developing physical activity levels. In A.L. Smith \& S.J.H. Biddle (Eds.), Youth physical activity and sedentary behavior: Challenges and solutions (pp. 141-166). Champaign, IL: Human Kinetics.

Malina, R.M. (2014). Top 10 research questions related to growth and maturation of relevance to physical activity, performance, and fitness. Research Quarterly for Exercise and Sport, 85(2), 157-173. PubMed ID: 25098012 doi:10.1080/02701367.2014.897592

Martinek, T., \& Hellison, D. (2016). Learning responsibility through sport and physical activity. In N.L Holt (Ed.). Positive youth development through sport (2nd ed., pp. 180-190). New York, NY: Routledge.

McGrane, B., Powell, D., Belton, S., \& Issartel, J. (2018). Investigation into the relationship between adolescents' perceived and actual fundamental movement skills and physical activity. Journal of Motor Learning and Development, 6(Suppl. 2), S424-S439. doi:10.1123/jmld.2016-0073

Nicholls, J.G. (1978). The development of the concepts of effort and ability, perceptions of academic attainment, and the understanding that difficult tasks require more ability. Child Development, 49(3), 800-814. doi:10.2307/1128250

Nicholls, J.G. (1984). Achievement motivation: Conceptions of ability, subjective experience, task choice, and performance. Psychological Review, 91(3), 328-346. doi:10. 1037/0033-295X.91.3.328

Palmer, K.K., Chinn, K.M., \& Robinson, L.E. (2017). Using achievement goal theory in motor skill instruction: A systematic review. Sports Medicine, 47(12), 2569-2583. PubMed ID: 28779359 doi:10.1007/s40279-017-0767-2

Palmer, K.K., Chinn, K.M., \& Robinson, L.E. (2019). The effect of the CHAMP intervention on fundamental motor skills and outdoor physical activity in preschoolers. Journal of Sport and Health Science, 8(2), 98-105. PubMed ID: 30997255 doi:10. 1016/j.jshs.2018.12.003

Roberton, M.A. (1988). The weaver's loom: A developmental metaphor. In J.E. Clark \& J.H. Humphrey (Eds.), Advances in motor development research (Vol. 2, pp. 129-141). New York, NY: AMS Press.

Robinson, L.E., \& Goodway, J.D. (2009). Instructional climates in preschool children who are at risk. Part I: Object-control skill development. Research Quarterly for Exercise and Sport, 80(3), 533-542. PubMed ID: 19791639 
Robinson, L.E., Palmer, K.K., \& Meehan, S.K. (2017). Dose-response relationship: The effect of motor skill intervention duration on motor performance. Journal of Motor Learning and Development, 5(2), 280-290. doi:10.1123/jmld.2016-0004

Robinson, L.E., Palmer, K.K., Webster, E.K., Logan, S.W., \& Chinn, K.M. (2018). The effect of CHAMP on physical activity and lesson context in preschoolers: A feasibility study. Research Quarterly for Exercise and Sport, 89(2), 265-271. PubMed ID: 29617193 doi:10.1080/02701367.2018.1441966

Robinson, L.E., Stodden, D.F., Barnett, L.M., Lopes, V.P., Logan, S.W., Rodrigues, L.P., \& D'Hondt, E. (2015). Motor competence and its effect on positive developmental trajectories of health. Sports Medicine, 45(9), 1273-1284. PubMed ID: 26201678 doi:10.1007/s40279-015-0351-6

Rowland, T.W. (1996). Developmental exercise physiology. Champaign, IL: Human Kinetics.

Rudisill, M.E. (2016). Mastery motivational climates: Motivating children to move and learn in physical education contexts. Kinesiology Review, 5(3), 157-169. doi:10.1123/ kr.2016-0009

Sameroff, A. (2010). A unified theory of development: A dialectic integration of nature and nurture. Child Development, 81(1), 6-22. PubMed ID: 20331651 doi:10.1111/j.14678624.2009.01378.x

Seefeldt, V. (1980). Developmental motor patterns: Implications for elementary school physical education. In C. Nadeau, W. Halliwell, K. Newell, and G. Roberts (Eds.), Psychology of motor behavior and sport-1979 (pp. 314-323). Champaign, IL: Human Kinetics.

Smith, A.L. (1999). Perceptions of peer relationships and physical activity participation in early adolescence. Journal of Sport \& Exercise Psychology, 21(4), 329-350. doi:10. 1123/jsep.21.4.329

Smith, A.L., Mellano, K.T., \& Ullrich-French, S. (2019). Peers and psychology experiences in physical activity settings. In T.S. Horn \& A.L. Smith (Eds.), Advances in sport and exercise psychology (4th ed., pp. 133-150). Champaign, IL: Human Kinetics.

Stodden, D.F., Goodway, J.D., Langendorfer, S.J., Roberton, M.A., Rudisill, M.E., Garcia, C., \& Garcia, L.E. (2008). A developmental perspective on the role of motor skill competence in physical activity: An emergent relationship. Quest, 60(2), 290-306. doi:10.1080/00336297.2008.10483582

Stuntz, C.P., \& Weiss, M.R. (2010). Motivating children and adolescents to sustain a physically active lifestyle. American Journal of Lifestyle Medicine, 4(5), 433-444. doi: $10.1177 / 1559827610368779$

Theeboom, M., De Knop, P., \& Weiss, M.R. (1995). Motivational climate, psychosocial responses, and motor skill development in children's sport: A field based-intervention study. Journal of Sport \& Exercise Psychology, 17(3), 294-311. doi:10.1123/jsep.17.3.294

Tremblay, M.S., Barnes, J.D., Gonzalez, S.A., Katzmarzyk, P.T., Onywera, V.O., Reilly, J.J., ... Global Matrix 2.0 Research Team. (2016). Global Matrix 2.0: Report card grades on the physical activity of children and youth comparing 38 countries. Journal of Physical Activity and Health, 13(11 Suppl. 2), S343-S366. PubMed ID: 27848745 doi:10.1123/ jpah.2016-0594

Ulrich, B.D. (1987). Perceptions of physical competence, motor competence, and participation in organized sport: Their interrelationships in young children. Research Quarterly, 58(1), 57-67. doi:10.1080/02701367.1987.10605421

Ulrich, B.D., \& Ulrich, D.A. (1997). Young children's perceptions of their ability to perform simple play and more difficult motor skills. In J.E. Clark \& J.H. Humphrey (Eds.), Motor development: Research and reviews (pp. 24-45). Reston, VA: NASPE Publications.

Ulrich, D.A. (2000). Test of gross motor development-2. Austin, TX: Prod-Ed.

Utesch, T., Bardid, F., Busch, D., \& Strauss, B. (2019). The relationship between motor competence and physical fitness from early childhood to early adulthood: A meta- 
analysis. Sports Medicine, 49(4), 541-551. PubMed ID: 30747376 doi:10.1007/ s40279-019-01068-y

Webster, E.K., Martin, C.K., \& Staiano, A.E. (2019). Fundamental motor skills, screentime, and physical activity in preschoolers. Journal of Sport and Health Science, 8(2), 114-121. PubMed ID: 30997257 doi:10.1016/j.jshs.2018.11.006

Weiss, M.R. (2004). Developmental sport and exercise psychology: A lifespan perspective. Morgantown, WV: Fitness Information Technology.

Weiss, M.R. (2008). "Field of dreams:" Sport as a context for youth development. Research Quarterly for Exercise and Sport, 79(4), 434-449. PubMed ID: 19177945 doi:10. 1080/02701367.2008.10599510

Weiss, M.R. (2011). Teach the children well: A holistic approach to developing psychosocial and behavioral competencies through physical education. The Academy Papers: Quest, 63(1), 55-65. doi:10.1080/00336297.2011.10483663

Weiss, M.R. (2013). Back to the future: Research trends in youth motivation and physical activity. Pediatric Exercise Science, 25(4), 561-572. PubMed ID: 24214439 doi:10. 1123/pes.25.4.561

Weiss, M.R. (2019a). Positive youth development through physical activity: Progress, puzzles, and promise. In T.S. Horn \& A.L. Smith (Eds.), Advances in sport and exercise psychology (4th ed., pp. 483-502). Champaign, IL: Human Kinetics.

Weiss, M.R. (2019b). Youth sport motivation and participation: Paradigms, perspectives, and practicalities. Kinesiology Review, 8(3), 162-170. doi:10.1123/kr.2019-0014

Weiss, M.R., Amorose, A.J., \& Kipp, L.E. (2012). Youth motivation and participation in sport and physical activity. In R.M. Ryan (Ed.) Oxford handbook of human motivation (pp. 520-553). New York, NY: Oxford University Press.

Weiss, M.R., \& Bredemeier, B.J. (1983). Developmental sport psychology: A theoretical perspective for studying children in sport. Journal of Sport Psychology, 5(2), 216-230. doi:10.1123/jsp.5.2.216

Weiss, M.R., Kipp, L.E., Phillips Reichter, A., Espinoza, S.M., \& Bolter, N.D. (2019). Girls on the Run: Impact of a physical activity youth development program on psychosocial and behavioral outcomes. Pediatric Exercise Science, 31(3), 330-340. PubMed ID: 30795719 doi:10.1123/pes.2018-0168

Weiss, M.R., McCullagh, P., Smith, A.L., \& Berlant, A.R. (1998). Observational learning and the fearful child: Influence of peer models on swimming skill performance and psychological responses. Research Quarterly for Exercise and Sport, 69(4), 380-394. PubMed ID: 9864756 doi:10.1080/02701367.1998.10607712

Weiss, M.R., \& Wiese-Bjornstal, D.M. (2009). Promoting positive youth development through physical activity. President's Council on Physical Fitness and Sports Research Digest, 10(3), 1-8. PubMed ID: 32335606

Weiss, M.R., \& Williams, L. (2004). The why of youth sport involvement: A developmental perspective on motivational processes. In M.R. Weiss (Ed.), Developmental sport and exercise psychology: A lifespan perspective (pp. 223-268). Morgantown, WV: Fitness Information Technology.

Wulf, G., \& Lewthwaite, R. (2016). Optimizing performance through intrinsic motivation and attention for learning: The OPTIMAL theory of motor learning. Psychonomic Bulletin Review, 23(5), 1382-1414. PubMed ID: 26833314 doi:10.3758/s13423-0150999-9

Zhang, T., Solmon, M.A., \& Gu, X. (2012). The role of teachers' support in predicting students' motivation and achievement outcomes in physical education. Journal of Teaching in Physical Education, 31(4), 329-343. doi:10.1123/jtpe.31.4.329 